\title{
Gauchos, cowboys y malandros ${ }^{1}$
}

\section{Gaúchos, cowboys e malandros}

\author{
Raquel Lima de Paula
}

\section{Resumen}

Este artículo establece un diálogo entre tres figuras míticas y pintorescas (gaucho, cowboy y malandro) que habitan distintas expresiones culturales y revelan características identitarias y costumbres (la gauchada, el jeitinho) de los países involucrados (Argentina, Uruguay, Brasil, Estados Unidos). Se consideran los aspectos históricos, políticos y literarios que están por detrás de las representaciones de estos seres populares y al margen del sistema social. El objetivo principal de este análisis es mostrar como personajes literarios, seres inventados e imaginados, suelen ser utilizados para crear verdades y acciones político-sociales, que favorecen los de siempre y reproducen ideologías fosilizadas a lo largo del tiempo. Para tanto, este trabajo hace uso del referencial de la teoría literaria, de la sociología y de las narrativas que representan los tres tipos míticos nombrados, señalando que las obras literarias nombradas van más allá de la tradición mimética y refuerzan el carácter excavador, expansivo de la literatura, que tiene el poder de dilatar fronteras, por ser en sí una herramienta de descubrimiento (como lo es el arte en general).

Palabras claves: Tipos. Identidad nacional. Jerarquía social.

\section{Resumo}

Este artigo apresenta um diálogo entre três figuras míticas e pitorescas (gaúcho, cowboy e malandro) que povoam diferentes manifestações culturais e revelam características identitárias e costumes (a gauchada, o jeitinho) dos países envolvidos (Argentina, Uruguai, Brasil, Estados Unidos). Levam-se em conta aspectos históricos, políticos e literários que estão por trás das representações desses seres populares e à margem do sistema social. O objetivo central desta análise é mostrar como os personagens literários, seres inventados e imaginados, costumam ser usados para criar verdades e ações político-sociais que favorecem os de sempre e reproduzem ideologias fossilizadas ao longo do tempo. Para tanto, este trabalho faz uso do referencial teórico da teoria literária, da sociologia e das narrativas que representam os três tipos míticos citados, destacando que as obras literárias referidas vão além da tradição mimética e reforçam o caráter escavador, expansivo da literatura, que tem o poder de dilatar fronteiras, por ser em si uma ferramenta de descobrimento (como o é a arte em geral).

Palavras-chave: Tipos. Identidade nacional. Hierarquia social.

\footnotetext{
1 Parte del presente artículo proviene de mi tesina de Maestría: Enrique Amorim sin reparto: La temática gauchesca en las novelas La Carreta y El Paisano Aguilar, sob orientación de Ruben Daniel Méndez Castiglioni en 2018, en el Programa de Pós-Graduação em Letras pela Universidade Federal do Rio Grande do Sul (UFRGS), Porto Alegre, RS, Brasil.

2 Doctoranda del Programa Post Graduación en Letras de la UFRGS. Profesora de Español en Fundação Escola Técnica Liberato Salzano Vieira da Cunha (FETLSVC), Novo Hamburgo, RS. ORCID: https://orcid.org/0000-0002-7256-8506. E-mail: raqueldepaula81@liberato.com.br 


\section{Del malandro al gaucho (ideas iniciales)}

El artículo a continuación es una invitación a reflexionar sobre las cuestiones identitarias a partir de las creaciones literarias, que absorbieron y resignificaron hechos históricos, sociales, culturales, comprobando la vitalidad y permanencia del tema. Para ello, se buscó soporte teórico multicultural, críticos del post colonialismo y latinoamericanos.

A partir de las discusiones sobre la emblemática figura del malandro, en la asignatura Canção Popular, me vino en mente otra figura que habita el imaginario popular y unas cuantas páginas literarias, así como también las canciones del folclore: el gaucho. La temática gauchesca es un punto que une a diferentes culturas del Cono Sur (usando un concepto más amplio, que abarca las semejanzas entre los países de la zona que comprende Argentina, Chile, Uruguay y la región Sur de Brasil) para este trabajo en particular interesa Rio Grande do Sul, cada cual con sus particularidades.

La palabra gaucho es polisémica, gana diferentes sentidos de acuerdo con la región y con el individuo que la emplea. La figura del malandro también es camaleónica, difícil encasillarla, definirla en palabras, pues ha ganado distintas versiones a lo largo del tiempo y de las regiones. La particularidad que une estas dos figuras míticas es lo cuanto son esquivos, se esquivan del sistema económico-social, no logran seguir las normas y padrones, más bien parece que se burlan del sistema.

Cuando comenzamos el análisis del malandro a lo largo de las obras literarias y de las canciones populares brasileñas, de pronto pensé en el icónico Capitão Rodrigo, de la novela épica de Érico Veríssimo (1905-1975), O tempo e o vento (1949) que abarca ciento cincuenta años de historia, tanto del Rio Grande do Sul como del resto de Brasil (desde 1745 a 1895). El personaje tiene un fuerte impacto en la trama, ya que hay un capítulo dedicado a él, dentro del tomo O Continente v. I, que se llama Um certo Capitão Rodrigo. Más tarde, el propio autor transforma el capítulo en una novela independiente. A la vez que es un tipo cargado de carisma, su carácter fuerte e irreductible frente a las leyes y los dogmas, causan desconfianza a la gente del poblado de Santa Fé desde su llegada, en octubre de 1828. Guitarra, batallas, cartas, caña y mujeres son sus pasatiempos favoritos, lo que de inicio promete un buen "entrevero", una buena pelea. Su forma de ser desagrada al coronel Ricardo Amaral, quien se cree el dueño del lugar, pues con su dinero y poderío "compra" la obediencia de la gente. Obviamente los dos hombres se desentienden en el momento en que se conocen, pero la riña aumenta cuando Rodrigo se enamora de Bibiana Terra, muchacha que también despierta el interés del hijo del coronel, Bento Amaral. Rodrigo decide echar raíces en el pueblo por Bibiana, quiere casarse con ella, cambiar el estilo vagamundo, errante, de hombre de guerras y de llanuras. Los cambios del capitán reflejan los cambios que sufren las campañas con las creaciones de los primeros poblados, el comienzo de la urbanización. Situación que "desubica" al gaucho, pues ya no se reconoce en la campaña y tampoco se encaja en la faena urbana. Después de casarse, Rodrigo se ve como un prisionero dentro de su hogar, no logra hacerse cargo de un trabajo fijo (el comercio), de la familia y de otras responsabilidades y valores burgueses (VERÍSSIMO, 2004).

Hay autores del Sur, como Érico Veríssimo, en el sur de Brasil y Enrique Amorim (1900-1960), en Uruguay, que expresan lo que Ángel Rama (1989) llama de transculturación narrativa o regionalismo plástico, que supera el naturalismo heredado del siglo XIX. También significa, en resumidas palabras, transmitir el conflicto entre la absorción de lo nuevo, como por ejemplo la influencia estética de las vanguardias europeas y el rescate, combinado con la "modernización", de la tradición, aspecto que se observa en las producciones de América Latina durante los años 1920 y 1930 (RAMA, 1989, p. 44).

Es evidente que estamos hablando de tiempos distintos, uno es el tiempo narrado (el principio de la urbanización vivido por el personaje de Érico es bastante anterior) y otro es el tiempo que se produjo el texto, que coincide con el pensamiento de Rama (1989). En los textos gauchescos de Amorim (2012a, 2012b), de los años treinta, se observan los cambios en la campaña por el contacto, la aproximación urbana. Las fronteras (campo/ciudad) se diluyen, se construyen caminos, vías de acceso. Se hace notar la llegada de los emigrantes (los gringos), que cambian el aspecto urbano y rural, causando ansiedad, miedo y forzando adaptaciones. El uruguayo, al presentar una campaña, un gaucho, ignorados hasta el momento y totalmente distintos de lo idealizado, desloca el mito. Revela un "otro" ser, que vive en un territorio desconocido, un "extranjero" dentro del mismo país, dentro de una misma localidad (AÍNSA, 2010).

En ese escenario, llama la atención la escritora (cuentista por excelencia) argentina Silvina Ocampo (1903-1993), hermana de la Ocampo más famosa e influyente, Victoria, casada con el también escritor Adolfo Bioy Casares y amiga muy cercana de Jorge 
Luis Borges. Silvina tiene muchas producciones con la temática urbana, encontró inspiración en los elementos vanguardistas: lo fantástico, lo maravilloso, lo onírico están presentes en sus relatos, pero una buena parte de sus textos se encuentra en el universo gauchesco, algo poco común entre las narrativas femeninas y, por ello, merece ser señalada aquí. Además, merece la visibilidad que viene ganando cada vez más en los espacios académicos brasileños, merece las investigaciones y publicaciones en todos los idiomas y desde los más variados rincones del mundo. Para tener una idea del aporte y la subversión de la escrita de Silvina, especialmente sobre la temática gauchesca, ver el artículo La escrita engendrada del gaucho en las narrativas transgresoras de Silvina Ocampo, del autor Rafael Guimarães:

[...] la ruptura con la tradición literaria rioplatense... la escrita engendrada subvierte las premisas patriarcales, problematizando la narrativa canónica gauchesca. (GUIMARÃES, 2014, p. 40).

Son escasos los nombres femeninos que se aventuraron a escribir sobre el ambiente rural, la campaña. En el artículo nombrado, el profesor hace un análisis sobre dos cuentos de Silvina: "La hija del toro" (1961) y "La muñeca" (1970), que se encuentran en los volúmenes I y II, respectivamente de la edición Cuentos Completos (OCAMPO, 1999a, 1999b). Através de sus cuentos, Silvina rompe con un código, no declarado, de que el universo y la labor brutos, las peleas y batallas, pertenecen a lo masculino, al hombre, una vez que lo que hay escrito sobre los gauchos salió de mentes y manos masculinas. Pero Silvina no se limita a transponer lo temática, también trasciende en lo estético (GUIMARÃES, 2014, p. 44). Abundan narradoras niñas, como se puede ver en los cuentos nombrados, lo que rompe, ya de inicio, la lógica esperada.

\section{Aspectos identitarios y políticos en los gauchos, cowboys y malandros (contextos históricos)}

Llamé la atención al gaucho por expresar una conducta rebelde frente a las autoridades. Ese rasgo de carácter que ya encontramos en Martín Fierro, héroe argentino. No tan rebelde, pero con muchas semejanzas (especialmente creaciones literarias y en las letras de canciones) encontramos la figura del cowboy estadounidense. Es cierto que existe una larga trayectoria de estudios académicos, documentales y películas que comprueban la aproximación de representatividad entre el gaucho y el cowboy. Aunque conviene señalar la diferencia social (se engendraron en sociedades distintas) que los separa, cuyas representaciones tomaron rumbos distintos, como apuntan los estudios realizados en la Universidad de San Andrés (Estados Unidos), por parte del programa de Extensión en Humanidades, cuya responsabilidad está en manos del porteño Martín Böhmer, director del área de Derecho de la Universidad, y de Michael Dinwiddie, de Muskogee, Oklahoma, dramaturgo, profesor de la Gallatin School de la Universidad de Nueva York. Ellos también organizan seminarios, como el que ocurrió en el año 2008: Seminario Internacional "Gauchos y cowboys: navegando en las mitologías políticas y culturales". Si se piensa en la importancia territorial, del espacio geográfico, en las batallas, en la cuestión indígena, en las fuerzas y oscilaciones de la naturaleza, en las marcas, rasgos, visibles en las costumbres, en el vocabulario, en lo cuanto todo eso influye, caracterizándolos y distinguiéndolos de los demás compatriotas.

En una entrevista al diario La Nación (ARBISER, 2008), los ya nombrados estudiosos, Böhmer y Dinwiddie, destacaron las similitudes de gauchos y cowboys, que son explícitas, como el desarraigo, el manejo con las armas, la conexión con el caballo. Sin embargo, la parte más interesante de la entrevista es cuando relacionan las creaciones artísticas, producciones literarias, de los personajes con las costumbres y las manifestaciones políticas e ideológicas de Argentina y de Estados Unidos (son los países donde desarrollan los estudios e investigaciones). En un dado momento de la entrevista, hay una referencia a la famosa riña entre las obras y los autores Facundo / Sarmiento (1955); Martín Fierro / José Hernández (1958): que la primera obra, de 1845, es la depreciación del gaucho, mostrándolo como ocioso, figura al margen de la sociedad y del progreso; mientras la segunda, escrita veintisiete años después, es la defensa. Recuerda además que Hernández la escribió durante la presidencia de Sarmiento, como una respuesta a este último. Las quejas del gaucho Martín Fierro sirven de aviso, un gaucho excluido reacciona mal, se porta como un gaucho malo, no acepta que le impongan nada con autoridad, se queja, se pone tanguero. Además, los estudiosos llaman la atención para la relación obra literaria y estructura social: el vocablo gauchada tiene que ver con violar las normas, conducta muy bien representada en la obra de Hernández y de Gutiérrez (con su Juan Moreira), hay en las dos obras un mensaje de desprecio hacia las autoridades. Por otro lado, en Facundo y en Las Bases (Juan Bautista Alberti) predomina el tono autoritario, poco inclusivo. Así, si un/a argentino/a, que ha 
elegido a Fierro como representación nacional, recibe una multa (prestación de cuentas con la autoridad) se inicia "un diálogo entre pares, uno hace la gauchada de completar el sueldo, el otro la gauchada de no poner la multa" (ARBISER, 2008).

De un lado está la práctica de la "gauchada" (asociada al favor, "una mano lava la otra"), del otro, el famoso jeitinho, asociado al estilo de vida del malandro y, consecuentemente del brasileño: "Nacido inicialmente de las contradicciones entre una orden liberal formal y una realidad esclavista, el jeitinho se transformó en código general de sociabilidad". Ambos, gauchada y jeitinho, sobreponen las relaciones personales, de afecto (para el bien o para el mal) a las leyes, a las normas sociales (supuestamente impersonales). De manera resumida, ese modo informal e improvisado de llevar la vida, que se ve en las esferas sociales menos favorecidas económicamente, tiene un origen histórico trágico y dominador, como apuntan las palabras de Francisco de Oliveira (2012). Lo más impresionante, aunque no siempre visible y evidente, ese estilo está en la formación de la sociedad brasileña $\mathrm{y}$ tiene inicio en los que vinieron dominar y colonizar el territorio. Según la teoría de Oliveira (más materialista, menos antropológica), hubo una "transferencia" de carácter por parte de los dominadores hacia los dominados, el jeitinho:

En Brasil, la clase dominante burló de manera permanente y recurrente a las leyes vigentes, sacadas a fórceps de otros cuadros históricos. La gambeta constante en las soluciones formales favorece la arrancada rumbo a la informalidad generalizada. Y se transforma, a lo largo de la perpetua formación y deformación nacionales, en predicado de los dominados (OLIVEIRA, 2012, p. 3, traducción de la autora).

Como bien señala el autor, no se trata sólo de echar la culpa a los que vinieron poblar y dominar Brasil (se puede pensar en Latinoamérica también), luego a los políticos y a la elite que sujetan las riendas del poder. Sin embargo, hay una costumbre enraizada de copiar los modelos económicos y sociales de sociedades dichas desarrolladas, sin cuidar las consecuencias y la realidad de las bases, pues no todos van a tener condiciones de "seguir la máquina”. Como ejemplo está la abolición de la esclavitud (1888), ¿qué hizo la clase dominante con los esclavos "libres? De poco sirvieron las dos leyes "de libertad" creadas durante la esclavitud; la "Ley del Vientre Libre": niños negros libres, pero con cero perspectivas de trabajo, salario, estar libre no servía para casi nada (OLIVEIRA, 2012, p. 9). Después vino la "Ley de los Sexagenarios", que dejaba libre a los negros con más de sesenta años. Ya se sabía que un esclavo llegaba cuando mucho a los cuarenta años, era la media de vida (OLIVEIRA, 2012, p. 10). Supongamos que llegase a los 60, ¿en qué estado estaría, con qué condiciones físicas lograría sobrevivir? Parece que las leyes se burlan de la población. De alguna manera la forma de gobernanza, la política, fomentó la proliferación del jeitinho. Si el sistema laboral no logró incorporar toda esa masa de mano de obra libre, la situación sólo empeoró con la industrialización y la tan soñada modernización. Más personas al margen, excluidas del engranaje, viviendo en la informalidad. El trabajo informal está en la estructura del capitalismo brasileño (OLIVEIRA, 2012, p. 10).

Los tipos creados tanto en la sociedad como en la ficción están cargados de verdades, provienen de las ideas, deseos, añoranzas, frustraciones, angustias, ambiciones del individuo, que es un sujeto político y social. También han servido de modelo (para el bien y para el mal) para manipular opiniones y lograr objetivos políticos (especialmente con el gaucho y el cowboy). El malandro estaría más para un antimodelo. En Argentina, por ejemplo, el peronismo fue un periodo en el cual la resistencia a la autoridad se hizo visible, se retomó la mitología del gaucho para luchar contra la autoridad del blanco, del porteño, que representaba la autoridad. Conviene recordar que un mismo tipo puede ser una amenaza social en un determinado momento, como lo era el gaucho durante la presidencia de Sarmiento, luego convertirse en un héroe nacional, todo depende del interés de los que detienen el poder, de los que dictan las normas, de las maniobras políticas, ésos son también los que eligen los "enemigos" de la patria: gaucho, indio, inmigrante (el gringo), el negro, los tres últimos son despreciados en los versos de Hernández. El reportaje relaciona el tema de la resistencia con la democracia y sostiene que para vivirla hay que aflojar las certezas, pero tanto en Facundo cuanto en Fierro estimulan lo cierto, cuando se sabe que el debate y la pelea están dentro del espíritu democrático. La idea cantada por el gaucho Fierro, que si entre los hermanos se pelean, los devoran los de afuera, visa estimular "lo cierto", lo homogéneo, lo semejante. Los ejemplos usados demuestran que no por casualidad Fierro es reconocida como la obra nacional por excelencia y, como lo recuerdan en el artículo, era algo que Jorge Luis Borges ya lo había señalado antes: "Si Facundo hubiera sido la obra nacional, otra hubiera sido la suerte de este país". Es complicado hacer ese tipo de 
afirmación, y sin duda la frase borgeana está cargada de ironía, igualmente no cabe en este trabajo avanzar en el análisis, lo que sí conviene llevar en cuenta, para las reflexiones siguientes, es el juego político e ideológico que se puede realizar con las producciones folclóricas, muy favorables para los discursos nacionalistas, por ejemplo. Actualmente lo gauchesco en Argentina está muy asociado a lo pintoresco, que fomenta el turismo internacional, con las parrilladas, los festivales de folclore, ya no se ven producciones culturales con reconocimiento internacional, como aún suele ocurrir con los cowboys en los Estados Unidos. La producción cinematográfica norteamericana sigue invocando westerns, aunque también entre los vaqueros ocurra una distorsión, una mitificación de la imagen. Llama la atención el uso que muchos políticos hacen de ese ícono, buscando recursos en la representación: el hombre que alcanza sus logros por cuenta propia (self-made man), los hombres que trabajan duro y ayudan a mantener la ley, como ejemplo aparece la figura de Ronald Reagan. Individualismo, característica tan bien explotada por el capitalismo, el que trabaja duro siempre logra sus objetivos, una máxima de la meritocracia. Convicciones individuales son muy valoradas en ese sistema, como se puede ver en las acciones estadounidenses, especialmente en la política internacional, una vez que suelen presumir llegar a una región y arreglarlo todo, llevar el orden, eliminar el caos. La actitud presumida tiene una relación con el imaginario western: el maverick (es una alusión a las vacas sueltas o libres, a aquellas personas independientes del rebaño). Un ejemplo relativamente reciente es la acción de los Estados Unidos sobre Irak. El discurso que justifica la acción está cargado de buenas intenciones, impresiona cómo están convencidos que son la representación de la bondad, los héroes que se sacrifican por extraños, en tierras extrañas.

Las observaciones de los estudiosos nombrados ayudan a pensar en los momentos en los cuales un pueblo, o una cultura, recurre (o crea) a sus héroes, mitos, algo que va mucho más allá de lo político. Tanto el gaucho como el cowboy y el malandro inspiraron una literatura pintoresca, única, además del aporte musical (sobre el cual no tengo conocimiento técnico, sino simplemente conozco algunos temas y aprecio los estilos). También es curioso, y rendiría otro estudio más para ahondar las razones, el hecho de que los tipos míticos nombrados son tipos masculinos, todos hombres, lo que, sin duda, dice mucho de una construcción social que se mantiene hasta nuestros tiempos, son huellas de la estructura patriarcal, una vez que los códigos de conducta que pautan lo masculino, encasillan también lo femenino, además de fomentar y buscar mantener el binarismo cultural.

Con relación a las producciones literarias hay una diferencia numérica entre los tres tipos, se encuentra un mayor número de textos con la temática gaucha, por la fuerte relevancia, representatividad cultural e impacto literario, como demuestran las obras sudamericanas (PAULA, 2018). Sin embargo, el cowboy es el que menos aparece en textos literarios, no hay grandes destaques novelísticos como los hay en el cine o en la música, por ejemplo. Es posible leer textos de relatos, recuerdos, autobiográficos producidos por los propios vaqueros, quienes, en general, sabían leer y escribir, a diferencia de los gauchos (SLATTA, 1984). Además, los contextos social y geográfico favorecieron a aquellos, una vez que se encontraban más próximos de las zonas industriales estadounidenses, lo que posibilitó una mejor adaptación a la modernización, tenían acceso a los productos industrializados, a las herramientas del día a día, a los alimentos, a la educación, a las letras, recursos disponibles para los que se encontraban más cerca de la dicha "civilización". Más alejados y hacia el margen del sistema se encontraban el gaucho y el malandro, pero tanto ése como aquél ganan protagonismo en las páginas literarias. El malandro está en las novelas, cuentos, teatro. Es decir, brilla en el escenario cultural brasileño, se hace presente en la música, en los personajes de telenovelas, aún es un tipo que habita el imaginario colectivo.

\section{El malandro y el subibaja social}

Ya se habló bastante del gaucho y del cowboy. Interesa para este trabajo echar una mirada sobre otra representación (personificación) que comparte el lado malevo y burlón frente a las órdenes y leyes: el malandro. Ellos dicen mucho del ser nacional de los países involucrados. Pasamos un semestre tratando de identificarlo en las páginas literarias y en las canciones brasileñas (referencias esencialmente cariocas, de Río de Janeiro). La misma dificultad encontrada para componer el gaucho, se encuentra para componer la figura del malevo brasileño. También aparece al margen del sistema social, no tiene un aprecio por el trabajo, gana la vida en la informalidad. Llama la atención por lucir un aspecto varonil, despierta una mezcla de sentimientos: respeto, miedo y admiración por parte de todos (principalmente de las mujeres), tiende a la riña, tiene un cierto grado de violencia (OTSUKA, 2007, p. 105). Hay obras que lo expresan 
siempre acompañado de la navaja (el cuchillo y armas de fuego en el caso del gaucho malo). La palabra malandro proviene del italiano dialectal y está siempre vinculada a la delincuencia, según el diccionario de la RAE. Una violencia asociada a un engranaje social, a un país dividido en clases sociales, que encontró en la esclavitud la base de su economía, cuyos ecos se escuchan hasta los días de hoy.

El análisis sobre el malandro empezó con la lectura de la novela Memórias de um sargento de Milícias (1852-1855), de Manuel Antônio de Almeida (2006). Para este trabajo no interesa tanto la novela en sí, sino las reflexiones de Antônio Cândido (1970) con su ensayo Dialética da malandragem y de Edu Otsuka (2007), que ahonda un poco más las ideas de Cândido. Lo primero que llama la atención del texto de Cândido (1970) es el intento de separar la figura del malandro de la figura del pícaro de las letras hispánicas. El segundo generalmente narra su propia suerte y, después de tanto penar y servir, logra integrarse a la lógica social, algo que no ocurre con el primero. Por lo tanto, el protagonista Leonardo de la novela de Manuel Antônio de Almeida (2006) no se trata de un pícaro, sino del primer malandro que aparece en la novelística brasileña (p. 71). Para el autor, la fuerza y actualidad de la novela se debe al hecho de estar basada "en la intuición de la dinámica social de Brasil en la primera mitad del siglo XIX” (p. 73). Hay en la novela un nivel más restricto y profundo de las representaciones de la vida: el brasileño. Y justamente es ese nivel que se constituye de la dialéctica del orden $y$ el desorden, que es parte estructural de la novela y se hace visible en las relaciones humanas. El sistema de relaciones de los personajes revela una dinámica social descrita en el libro:

(1) De un orden comunicándose con un desorden que lo rodea por todos lados; (2) la correspondencia profunda, mucho más que documental, a ciertos aspectos asumidos por la relación entre el orden y el desorden en la sociedad brasileña de la primera mitad del siglo 19. (CÂNDIDO, 1970, p. 77).

No se pretende ahondar los aspectos de la novela y de los personajes, lo que se pretende con el análisis de Cândido (1970) es echar una mirada más atenta hacia el primer malandro de las letras brasileñas, que señala (de manera sutil y bien construida) una práctica social enraizada en la formación brasileña. Los personajes se organizan entre dos polos, el del orden (de los que siguen las normas establecidas, polo "positivo") y del desorden (de los que se oponen o que no se integran a ésas, polo "negativo"). El protagonista y sus padres están en el medio y circulan entre los dos mundos en un constante subibaja. Se atenta para una lectura que entiende que el hecho de que un personaje se encuentre en el polo "positivo" (ejemplo del orden, de las normas, respetado por las autoridades, bajo ningún tipo de sospecha), no está inmune al desorden, a "resbalar" hacia abajo (cuando dominado por pasiones, deseos, impulsos, por ejemplo). Queda evidente que las estrategias, trucos, engaños, trampas para lograr y mantener el aparente "orden" está vinculado, articulado al desorden, ambos en continua interdependencia, dónde empieza uno y termina el otro es muy relativo, pues hay momentos de roces, en los cuales los extremos se rozan. Aquí es válido recordar aquellas figuras "ejemplares" del orden (los que están arriba en la jerarquía social) que actúan malandramente en nombre de los intereses personales, son los mismos que juzgan, condenan e inhiben los que así actúan, pero pertenecen a las camadas más bajas de la sociedad.

\section{Reflexiones finales}

Las tres figuras populares presentadas tienen un rasgo de rebeldía frente a las normas y el orden del sistema social. El gaucho y el malandro comparten aspectos burlescos, no tan evidentes en los cowbo$y s$, así como también se revelan más transgresores (con respecto a las normas / leyes) que ésos. Todos llevan como escudo la hombría, la masculinidad y a su vez despiertan una mezcla de reproche y fascinación (por el lado pintoresco, algunas veces romántico, revelado en algunas letras y canciones). Se hizo ver, a través de los análisis históricos y sociales, que hay un fondo trágico (triste) por detrás de los míticos gauchos y malandros, que los colocan al margen de un engranaje económico-social, que es injusto por favorecer siempre a los mismos, pero al mismo tiempo los mismos aspectos condenables (la gauchada y el jeitinho) cultural y socialmente aparecen en todas las clases económicas, explícitamente en una minoría más afortunada y poderosa (como la de los políticos, mandatarios, banqueros por ejemplo), que goza de una eterna impunidad, impunidad que también está ampliamente esparcida.

Vengo por estas palabras, rescatar y cantar el lado fascinante (desde una óptica particular) de los gauchos y malandros, el lado indomable, burlesco, jocoso, que sale de lo previsto, no hacen lo esperado. Pienso que en estos tiempos de "libre mercado", lo que menos se ha ganado es libertad, estamos cada vez más condenados (estimulados por el consumo y las nuevas 
tecnologías) a gastar, a consumir, a agotar los recursos naturales y a la soledad (CRARY, 2016). Dejo aquí una frase del uruguayo Eduardo Galeano (1940-2015), en una de sus últimas entrevistas, en el periódico $E l$ Mundo (16/04/2015), de España: "La realidad es que vivimos sometidos a un sistema económico mundial que nos obliga a la obediencia y a creer en la verdad única”. (ROMERO; ROMERO, 2015).

\section{Referências}

AÍNSA, F. Discurso identitario y discurso literario en América Latina. Amerika, n. 1, 2010. DOI: 10.4000/ amerika.478. Disponível em: https://amerika.revues. org/478. Acesso em: 20 mar. 2018.

ALMEIDA, M. A. Memórias de um sargento de Milícias. Cotia: Ateliê, 2006.

AMORIM, E. El paisano Aguilar. Alcalá la Real: Alcalá, 2012a.

AMORIM, E. La carreta. Alcalá la Real: Alcalá, 2012b.

ARBISER, F. La Argentina y EEUU: como el gaucho y el cowboy. La Nacion, Buenos Aires, 19 out. 2008. Disponível em: http://www.lanacion.com.ar/1060755la-argentina-y-eeuu-como-el-gaucho-y-el-cowboy. Acesso em: 16 mar. 2018.

CÂNDIDO, A. Dialética da malandragem. Revista do Instituto de Estudos Brasileiros, n. 8, p. 67-89, 1970. DOI: 10.11606/issn.2316-901X.v0i8p67-89. Disponível em: http://www.educacional.com.br/ upload/dados/materialapoio/580001/8384666/ Artigo \%20-\%20Dial\%C3\%A 9tica\%20da\%20 malandragem\%20\%28Antonio\%20Candido\%29.pdf. Acesso em: 19 ago. 2019

CRARY, J. 24/7: capitalismo tardio e os fins do sono. São Paulo: Ubu, 2016.

GUIMARÃES, R. E. A escrita gendrada do gaucho nas narrativas transgressoras de Silvina Ocampo. Anuário de Literatura, v. 19, n. 2, p. 38-51, 2014. DOI: 10.5007/2175-7917.2014v19n2p38. Disponível em: https:/periodicos.ufsc.br/index.php/literatura/article/ view/2175-7917.2014v19n2p38. Acesso em: 5 ago. 2021
HERNÁNDEZ, J. Martín Fierro. Buenos Aires: Losada, 1958.

OCAMPO, S. La hija del toro. Buenos Aires: Emecé, 1999a. (Cuentos Completos, v. 1).

OCAMPO, S. La muñeca. Buenos Aires: Emecé, 1999b. (Cuentos Completos, v. 2).

OLIVEIRA, F. Jeitinho e jeitão: uma tentativa de interpretação do caráter brasileiro. Piauí, n. 73, out. 2012. Disponível em: https://piaui.folha.uol.com.br/ materia/jeitinho-e-jeitao/. Acesso em: 19 ago. 2019

OTSUKA, E. T. Espírito rixoso: para uma reinterpretação das Memórias de um sargento de Milícias. Revista do Instituto de Estudos Brasileiros, n. 44, p. 105-124, fev. 2007. DOI: 10.11606/issn.2316901X.v0i44p105-124. Disponível em: https://www. revistas.usp.br/rieb/article/view/34564. Acesso em: 19 ago. 2019

PAULA, R. L. Enrique Amorim sin reparto: la temática gauchesca en las novelas La Carreta y El Paisano Aguilar. 2018. 106 f. Dissertação (Mestrado em Literaturas de Língua Espanhola) - Instituto de Letras, Universidade Federal do Rio Grande do Sul, Porto Alegre, 2018.

RAMA, A. Transculturación narrativa en América Latina. Montevideo: Fundación Ángel Rama: Arca, 1989.

ROMERO, V.; ROMERO, M. "La rebeldía es un acto que proviene del amor". Entrevistado: Eduardo Galeano. El Mundo, Madrid, 16 abr. 2015. Disponível em: https://www.elmundo.es/ cultura/2015/04/16/552eac9122601dbe508b4577. html. Acesso em: 8 dez. 2019.

SARMIENTO, D. F. Facundo. Buenos Aires: Pauser, 1955.

SLATTA, R. W. Gauchos llaneros y cowboys: un aporte a la historia comparada. Boletín Americanista, n. 34, p. 193-208, 1984. Disponível em: https://raco.cat/ index.php/BoletinAmericanista/article/view/98446. Acesso em: 22 mar. 2018.

VERÍSSIMO, E. O tempo e o vento: o continente. São Paulo: Globo: Companhia da Letras, 2004. 2 v. 
